\begin{tabular}{cc|c}
\hline Tar. Bil. Der. & Journal of Agricultural Sciences \\
& $\begin{array}{c}\text { Dergi web sayfası: } \\
\text { www.agri.ankara.edu.tr/dergi }\end{array}$ & Journal homepage: \\
& www.agri.ankara.edu.tr/journal
\end{tabular}

\title{
Öküzgözü Üzümlerinden Kırmızı Şarap Üretiminde Soğuk Maserasyon Uygulamasının Antosiyaninler Üzerine Etkisi
}

\author{
Haşim KELEBEK ${ }^{\mathrm{a}}$, Serkan SELLí ${ }^{\mathrm{b}}$, Ahmet CANBAŞ ${ }^{\mathrm{b}}$ \\ ${ }^{a}$ Adıyaman Üniversitesi, Adıyaman Meslek Yüksekokulu, Gıda Teknolojisi Bölümü, Altınşehir 02040, Adıyaman, TÜRKİYE \\ ${ }^{b}$ Çukurova Üniversitesi, Ziraat Fakültesi, Glda Mühendisliği Bölümü, 01300 Adana, TÜRKİYE
}

ESER BİLGİSi

Araştırma Makalesi — Tarımsal Gıda ～DOI: 10.1501/Tarimbil_0000001149

Sorumlu Yazar: Haşim KELEBEK, e-posta: hkelebek@adiyaman.edu.tr, Tel: +90(544) 26707

68 Geliş tarihi: 08 Nisan 2010, Düzeltmelerin gelişi: 18 Ocak 2011, Kabul: 26 Ocak 2011

\begin{abstract}
ÖZET
$\mathrm{Bu}$ çalışmada, Öküzgözü üzümünün şaraba işlenmesi sırasında uygulanan soğuk maserasyon uygulamasının antosiyanin bileşimi üzerindeki etkileri incelenmiştir. Antosiyanin bileşiklerinin analizleri zıt fazlı ve diyod array dedektörlü HPLC cihazı ile yapılmış ve 5 adet monoglikozit, 5 adet asetil ve 4 adet kumaril yapısında olmak üzere toplam 14 adet antosiyanin bileşiği belirlenmiştir. Bu bileşiklerin toplam miktarı soğuk maserasyon uygulamasıyla elde edilen şaraplarda $284.15 \mathrm{mg} l^{-1}$ ve kontrol şaraplarında ise $243.62 \mathrm{mg} l^{-1}$ olarak saptanmıştır. Her iki uygulama ile elde edilen şaraplarda miktar olarak en fazla bulunan antosiyanin bileşiğinin malvidin-3-glikozit, en az bulunanın ise siyanidin-3-glikozit olduğu belirlenmiştir. Soğuk maserasyon yöntemiyle üretilen şaraplarda renk yoğunluğu, toplam fenol bileşikleri ve tanen miktarı daha yüksek bulunmuştur. Duyusal değerlendirme sonucunda, soğuk maserasyon yöntemiyle üretilen şaraplar renk, aroma, dolgunluk, son burukluk ve genel izlenim bakımından daha yüksek puanlar almıştır.
\end{abstract}

Anahtar sözcükler: Öküzgözü; Fenol bileşikleri; Antosiyanin; Soğuk maserasyon; HPLC

\section{Effect of Cold Maceration Treatment on Anthocyanins in Red Wine Production of Öküzgözü Grapes}

\section{ARTICLE INFO}

Research Article - Agricultural Food

Corresponding author: Haşim KELEBEK, e-mail: hkelebek@ adiyaman.edu.tr, Tel: +90(544) 2670768

Received: 08 April 2010, Received in revised form: 18 January 2011, Accepted: 26 January 2011

\begin{abstract}
In this study, anthocyanin compounds of wines made from cv. Öküzgözü and effects of by cold maceration on the anthocyanin profiles of these wines were investigated. Anthocyanin composition was detected by high performance liquid chromatography (HPLC) coupled with diode array detector. Fourteen different anthocyanins, including five glucosides, five acetyl glucosides, and four coumaroyl glucosides were identified and quantified. Total concentration of these compounds was $284.15 \mathrm{mg} l^{-1}$ for cold maceration wines and $243.62 \mathrm{mg} l^{-1}$ for control wines. Malvidin-3glucoside was the most abundant and cyanidin-3-glucoside was minor anthocyanins in both wines. Total colour intensity, phenolic and tannin content of wines produced with cold maceration were clearly higher than control
\end{abstract}


wines. Based upon sensory analysis, the wines obtained from cold maceration had higher colour, flavour, body, astringency aftertaste and harmony character than that the one produced from traditional maceration.

Keywords: Öküzgözü; Phenolic compounds; Anthocyanin; Cold maceration; HPLC

(c) Ankara Üniversitesi Ziraat Fakültesi

\section{Giriş}

Şarapların bileşiminde bulunan ve kaliteyi etkileyen en önemli unsurlardan birisi, fenol bileşikleridir. Fenol bileşikleri siyah üzümlerin ve bu üzümlerden elde edilen şarapların renkleri ve duyusal özellikleri üzerinde önemli rol oynamaktadır. Kırmızı şarapların rengi, tatlarındaki dolgunluk ve burukluk gibi özellikleri fenol bileşiklerinden kaynaklanmaktadır. Fenol bileşikleri arasında en önemlileri kırmızı renkli antosiyaninler ve renksiz nitelikteki tanenlerdir (Ribéreau-Gayon \& Glories 1986). Antosiyaninler, siyah üzümlerdeki renk pigmentleridir. $\mathrm{Bu}$ bileşikler üzüm ve şarapların kendilerine özgü kırmızı, mavi ve mor tonlardaki renklerini veren, suda ve şırada az ve alkolde çok çözünen doğal renk maddeleridir (Ribéreau-Gayon et al 2000).

Geleneksel kırmızı şarap üretiminde, üzümün katı kısımlarında bulunan ve şaraba kendine özgü niteliklerini kazandıran fenol bileşiklerinin çözünmesini sağlamak amacıyla cibre fermantasyonu uygulanmaktadir. Cibre fermantasyonu sırasında renkli fenol bileşikleri (antosiyaninler) ile birlikte renksiz fenol bileşikleri (tanenler, fenol asitleri) de şaraba geçmektedir. Şarabın dinlendirilmesi sırasında ise bir çok fiziksel ve kimyasal değişime uğramaktadır (Sims \& Bates 1994; Ribéreau-Gayon et al 2000).

Soğuk maserasyon, genel anlamıyla klasik cibre fermantasyonunun ilk dönemlerinin düşük sıcaklıklarda gerçekleştirilmesi tekniğidir. Bazı çalışmalarda, 10 ile 14 güne kadar uzayan soğuk maserasyon süresi, genel olarak $4-15^{\circ} \mathrm{C}$ 'ler arasında ve 2-7 gün sürdürülür. $\mathrm{Bu}$ işlemi düşük s1caklıklarda yürütmenin amac1, bazı organizmaların (heterofermantatif laktik asit bakterileri, Acetobacter, Brettanomyces, Kloeckera ve Hanseniaspora) oluşturacağı riskleri azaltmak ve şaraplarda renk ve aroma kayıplarına neden olan enzimlerin faaliyetlerini sinırlamaktır. Bu teknikle yapılan şarapların, renk ve aroma yönünden, klasik yöntemle elde edilene göre daha iyi olduğu bildirilmiştir (Rotter 2008). Bağcılığın ve şarapçılığın gelişmiş olduğu çeşitli ülkelerde soğuk maserasyon uygulamasının şaraplardaki fenol ve aroma bileşikleri üzerine etkilerini konu alan çok sayıda araştırmalar yapılmıştır (Girard et al 2001; Rotter 2008; Álvarez et al 2009; Heredia et al 2010). Ülkemizde ise bu konuyla ilgili sistemli bir araştırmaya rastlanmamıştır. Bu çalışma; ülkemizin önemli şaraplık çeşitlerinden Öküzgözü üzümünün kırmızı şaraba işlenmesi sırasında soğuk maserasyon uygulamasının şarapların genel bileşimleri ve antosiyanin dağılımları üzerine etkisini ortaya koymak amacıyla yapılmıştır.

\section{Materyal ve Yöntem}

\subsection{Materyal}

Bu çalışma 2008 yılı, Elazı̆̆ yöresi Öküzgözü (300 kg) üzümleri kullanılarak Çukurova Üniversitesi Ziraat Fakültesi Gıda Mühendisliği Bölümü pilot şarap işletmesinde iki tekerrürlü olarak gerçekleştirilmiştir.

\subsection{Yöntem}

Üzümler sap ayırma işleminden sonra ezilmiş ve 25 mg $l^{-1}$ olacak şekilde $\mathrm{SO}_{2}$ ilave edilmiştir. Daha sonra üzümler 150'şer kg'lık iki kısma ayrılmış ve geleneksel ve soğuk maserasyon uygulamaları olarak iki farklı şekilde işlenmiştir. Geleneksel yöntemde (Kontrol) üzümler $25^{\circ} \mathrm{C}$ de 12 gün maserasyona terk edilmiştir. Soğuk maserasyon uygulamasinda ise $7^{\circ} \mathrm{C}$ 'de 5 gün maserasyona bırakılmış ve bu sürenin sonunda geleneksel yöntemle 7 gün daha maserasyona bırakılmıştır. Maserasyon işlemi süresince, kabın yüzeyinde bulunan kitle günde iki kez kırılmış ve alttan alınan Şıra üstten verilmek suretiyle karıştırılıp homojen hale getirilmiştir. Alkol fermantasyonu sonunda şaraplar havalı olarak aktarılmış ve malolaktik fermantasyonun gerçekleşmesi için $20^{\circ} \mathrm{C}$ 'lik bir mahzene alınmıştır. Malolaktik fermantasyondan 
sonra şaraplar yeniden aktarılmış yaklaşık $75 \mathrm{mg} l^{-1}$ $\mathrm{SO}_{2}$ hesabıyla kükürtlenmiştir.

\section{3. Şıra ve şarapta yapılan analizler}

Şırada toplam asitlik, pH, kuru madde, kül, indirgen şeker analizleri (Ough \& Amerine 1988; OIV 1990; Selli et al 2002), toplam fenol bileşikleri (RibéreauGayon et al 2000), renk bileşimi, renk yoğunluğu ve renk tonu analizleri yapılmıştır (Ribéreau-Gayon et al 2000). Şaraplarda bu analizlere ek olarak yoğunluk, alkol, uçar asit, serbest ve toplam $\mathrm{SO}_{2}$ analizleri ve duyusal analizler yapılmıştır (Ough \& Amerine 1988).

Antosiyaninlerin analizlerinde çift pompalı, Diyod Array dedektörlü Agilent 1100 (Agilent Technologies, Palo Alto CA-USA) marka HPLC cihazı kullanılmıştır. Analizlerde kullanılan HPLC'nin çalışma koşulları aşağıdaki gibidir (Kelebek et al 2006):

-Kullanılan kolon: Beckman Ultrasphere $\mathrm{C}_{18}$ ODS $(250 \times 4.6 \mathrm{~mm} \times 5 \mu)$

-Enjekte edilen miktar: $20 \mu l$

-Taşıyıcı faz : A = Su / Formik aist (95/5: h/h)

$\mathrm{B}=$ Metil alkol/Formik asit $(95 / 5: \mathrm{h} / \mathrm{h})$

-Akış hızı: $1 \mathrm{~m} l \mathrm{~min}^{-1}$

-Dalga boyu: $520 \mathrm{~nm}$

Antosiyaninlerin tanıs1, kullanılan standart maddelerin alıkonma zamanları ve spektrumlarından ve literatür verilerinden yararlanılarak yapılmıştır. Standart madde olarak delfinidin, siyanidin, petunidin, peonidin ve malvidin 3-glikozit kullanılmıştır (Extrasynthese, France). Standardı olmayan bileşiklerin tanısı bu bileşiklerin alıkonma zamanlarının ve UV spektrumlarının literatür verileri ile kıyaslanmasıyla sağlanmıştır. Miktar tayininde, her bir standart madde için beş farklı konsantrasyonda çözelti hazırlanmış ve HPLC'ye enjekte edilerek her bir bileşik için kalibrasyon eğrileri oluşturulmuştur. Bu eğrilerden de bileşiklerin miktarları belirlenmiştir.

\subsection{Duyusal analizler}

Denemelerden elde edilen şarapların duyusal analizlerinde "lezzet profil testi" uygulanmış ve sonuçlar örümcek ağı diyagramında verilmiştir (Jackson 2002). Panelistler öncelikle terminoloji ve skala kullanımı konusunda eğitilmiştir ve örneklerde yapılan denemeler sonucunda, tanımlayıcılar (renk, aroma, dolgunluk, tatlılık ve ekşilik vb.) net olarak her örnek için tespit edilmiştir (Çopanoğlu \& Boyacıŏ̆lu 2006). Analizler 10 puanlık skala kullanılarak 7 kişiden oluşan uzman bir jüri tarafından gerçekleştirilmiştir.

\section{Bulgular ve Tartışma}

\section{1. Şıranın genel bileşimleri}

Öküzgözü üzümlerinden elde edilen şıranın genel bileşimi Çizelge 1'de verilmiştir. Görüldüğü gibi, Öküzgözü şırasının indirgen şeker miktarı $220.9 \mathrm{~g} l^{-}$ ${ }^{1}$,dir. Ribéreau-Gayon et al (2000), şaraplık üzümlerde şeker miktarının litrede 150-250 g arasında değiştiğini bildirmişlerdir. Şıradaki toplam asit miktarı 86.3 me $l^{-1}, \mathrm{pH}$ değeri 3.2 olarak bulunmuştur. Amerine et al (1980) şaraplık üzümlerde asitliğin 40-213 me $l^{-1}$ arasında değiştiğini bildirmişlerdir. Öküzgözü üzümünden elde edilen şıradaki antosiyanin miktarı $78.7 \mathrm{mg} \mathrm{l}^{-1}$, renk yoğunluğu 0.9 ve renk tonu 0.96'dır.

\section{2. Şarapların genel bileşimleri}

Çizelge 2'de geleneksel ve soğuk maserasyon uygulamaları ile elde edilen şarapların genel bileşimleri verilmiştir. Soğuk maserasyon uygulamasinın toplam asit, $\mathrm{pH}$, toplam fenol bileşikleri, tanen, \% OY 520, \% OY 620 ve \% dA parametreleri hariç, genel bileşim üzerinde önemli

\section{Çizelge 1-Şıranın genel bileşimi}

Table 1-General composition of must

\begin{tabular}{lr}
\hline Analizler & \\
\hline Toplam asitlik, me $l^{-1}$ & $86.3 \pm 1.20$ \\
$\mathrm{pH}$ & $3.2 \pm 0.02$ \\
Olgunlaşma katsayısı, öksele/asit & $15.1 \pm 0.60$ \\
İndirgen şeker, g $l^{-1}$ & $220.9 \pm 5.72$ \\
Antosiyanin, mg $l^{-1}$ & $78.7 \pm 2.46$ \\
Toplam fenol bileşikleri indisi (OY280) & $40.8 \pm 2.06$ \\
Renk yoğunluğu (OY420+OY520+OY620) & $0.9 \pm 0.12$ \\
Renk tonu (OY420/OY520) & $0.96 \pm 0.02$ \\
$\%$ OY420 & $42.1 \pm 0.16$ \\
$\%$ OY520 & $43.6 \pm 0.22$ \\
$\%$ OY620 & $14.3 \pm 0.02$ \\
$\%$ dA & $43.3 \pm 0.21$ \\
\hline
\end{tabular}


bir etkisi olmamıştır. Elde edilen sonuçlar Kalecik karası üzümünden elde edilen sonuçlar ile benzerlik göstermektedir (Anlı 2004). Toplam asit miktarı geleneksel maserasyon uygulaması ile elde edilen şaraplarda daha yüksek bulunmuştur. Asitlik şarabın tat ve dayanıklılığı üzerinde etkilidir. Ayrıca, şaraba tazelik kazandırır ve renk tonu üzerinde etkili olmaktadır. Sek şaraplarda asit miktarı tartarik asit cinsinden $4.5 \mathrm{~g} l^{-1}$ ile $9 \mathrm{~g} l^{-1}$ arasında değişmekle birlikte en uygun asit miktarı 6-7 g $l^{-1}$ civarındadir (Ough \& Amerine 1988). Toplam fenol bileşikleri indisi ve tanen miktarı soğuk maserasyon uygulaması ile elde edilen şaraplarda daha yüksek bulunmuştur. Canbaş (1983) kırmızı şaraplardaki tanen miktarının üzüm çeşidine ve şarap yapım tekniğine bağlı olarak 1.5-5 $\mathrm{g} l^{-1}$ arasında değiştiğini bildirmiştir. Renk bileşimi sar1 (\% OY 420), kırmızı (\% OY520) ve mavi (\% OY620) renklerin oluşturduğu toplam rengi ifade etmektedir. \% dA, şıra ve şaraplardaki kırmızı rengin parlaklığını ifade etmektedir. $\mathrm{Bu}$ değer kırmızı şaraplarda 40 ile 60 arasında değişmekte ve yüksek olması parlak kırmızı rengin, düşük olması ise kiremit kırmızısı rengin baskın olduğunu göstermektedir (Ribéreau-Gayon et al 2000). Soğuk maserasyon uygulamasıyla elde edilen şaraptaki \% dA değeri, kontrol şaraplarına göre daha yüksek bulunmuştur.

\section{3. Şarapların antosiyanin bileşimleri}

Çizelge 3'de Öküzgözü üzümlerinden elde edilen şarapların antosiyanin bileşimleri verilmiştir. Toplam antosiyanin miktarı geleneksel maserasyon yöntemiyle üretilen şaraplarda $243.62 \mathrm{mg} l^{-1}$ ve soğuk maserasyon yöntemiyle üretilen şaraplarda ise $284.15 \mathrm{mg}^{-1}$ olarak belirlenmiştir. Álvarez et al (2006) İspanya' da yetiştirilen Monastrell üzümlerinden elde edilen tanık şarapta toplam antosiyanin miktarını $229.17 \mathrm{mg} l^{-1}$ ve $5-8^{\circ} \mathrm{C}$ arasinda uygulanan soğuk maserasyonla üretilen şaraplardaki miktarını ise $257.78 \mathrm{mg} l^{-1}$ olduğunu bildirmişlerdir. Parenti et al (2004), Tuscan sangiovese üzümlerinden elde edilen tanık şarapta antosiyaninlerin toplam miktarını $98 \mathrm{mg}^{-1}$ ve soğuk maserasyon uygulamasıyla $\left(5^{\circ} \mathrm{C}^{\prime}\right.$ de azot gazı altında) elde edilen şaraplarda ise $154 \mathrm{mg} l^{-1}$ olarak saptamışlardır. Benzer sonuçlar Syrah (GomezMiguez et al 2007), Tempranillo (Álvarez et al
2009) ve Cabernet sauvignon (Gil-Munoz et al 2009) üzümlerinden soğuk maserasyon uygulamasiyla elde edilen şaraplarda da bulunmuştur.

Şaraplarda belirlenen antosiyanin bileşiklerinin 520 nm'deki kromatogramı Şekil 1'de verilmiştir. Şaraplarda 5 adet glikozit, 5 adet asetil-glikozit ve 4 adet kumaril-glikozit olmak üzere toplam 14 adet antosiyanin bileşiği belirlenmiştir. Şekil 1'de görüldüğü gibi, bileşikler polar özelliklerine bağlı olarak glikozit<asetil-glikozit<kumaril-glikozit sıralamasıyla taşınmışlardır. Malvidin-3-glikozit ve bunun asetil ve kumaril formları toplam antosiyaninlerin önemli bir kısmını oluşturmuştur. Soğuk maserasyon yöntemiyle elde edilen şaraplarda malvidin miktarı kontrol şaraplarından daha yüksektir. $\mathrm{Bu}$ durum yapılan benzer çalışmalarla uyum içerisindedir (Gomez-Miguez et al 2007; Álvarez et al 2009).

Antosiyaninler içerisinde glikozit formunda bulunanlar, bu bileşiklerin önemli bir kısmını oluşturmuştur. Glikozit formundaki antosiyaninlerin toplam miktarı kontrol şarabında $200.6 \mathrm{mg}^{-1}$ iken, soğuk maserasyonla elde edilen şarapta $234.48 \mathrm{mg} l^{-1}$, ye yükselmiştir. GomezMiguez et al (2007) Syrah üzümlerinden elde edilen tanık şarapta $\left(25^{\circ} \mathrm{C}\right.$ 'de 6 gün cibre fermantasyonu) toplam glikozit formunda bulunan antosiyaninlerin miktarının $124.8 \mathrm{mg} l^{-1}$ den, soğuk maserasyon uygulamasiyla $\left(15^{\circ} \mathrm{C}^{\prime}\right.$ de 6 gün) $187.93 \mathrm{mg} l^{1 \text {, ye }}$ yükseldiğini bildirmişlerdir. Malvidin-3-glikozit antosiyaninler içerisinde en baskın bileşiktir. $\mathrm{Bu}$ bileşiğin miktarı tanık şarapta $145.70 \mathrm{mg}^{1}$ ve soğuk maserasyon uygulanan şarapta ise $174.22 \mathrm{mg}$ $l^{-1}$ olarak belirlenmiştir. $\mathrm{Bu}$ bileşik tanık şarapta toplam antosiyaninlerin \% 59.8'ini ve soğuk maserasyonla elde edilen şarapta ise \% 61.3'ünü oluşturmuştur. Mazza (1995), Cabernet sauvignon, Merlot, Syrah ve Tempranillo üzümlerinden elde ettiği şaraplarda malvidin-3-glikozitin \% 44.4-69.4 arasında değiştiğini bildirmiştir. Benzer şekilde Gomez-Plaza et al (2001), Monastrell şaraplarında antosiyaninlerin önemli bir kısmını glikozitlerin oluşturduğunu ve bu bileşiklerin içerisinde malvidin-3-glikozitin \% 62-65 arasında değiștiğini saptamışlardır. Soğuk maserasyon uygulaması malvidin-3-glikozit miktarını \% 21.0 oranında 
Çizelge 2-Şarapların genel bileşimleri

Table 2-General composition of wines

\begin{tabular}{|c|c|c|c|}
\hline Analizler & Kontrol & Soğuk mas. & $P$ değerleri \\
\hline Yoğunluk, $20 / 20^{\circ} \mathrm{C}$ & $0.9921 \pm 0.01$ & $0.9922 \pm 0.01$ & 0.994 \\
\hline Alkol, $\% \mathrm{~h} \mathrm{~h}^{-1}$ & $12.7 \pm 0.25$ & $12.9 \pm 0.19$ & 0.382 \\
\hline Toplam asit, me $l^{-1}$ & $61.6 \pm 1.23$ & $59.1 \pm 0.85$ & 0.039 \\
\hline $\mathrm{pH}$ & $3.42 \pm 0.07$ & $3.56 \pm 0.05$ & 0.045 \\
\hline Uçar asit, $\mathrm{g} l^{-1}$ a & $0.13 \pm 0.00$ & $0.11 \pm 0.01$ & 0.163 \\
\hline Toplam fenol bileşikleri indisi & $56.4 \pm 1.13$ & $79.3 \pm 1.14$ & 0.000 \\
\hline İndirgen şeker, $\mathrm{g} l^{-1}$ & $2.6 \pm 0.05$ & $2.8 \pm 0.04$ & 0.088 \\
\hline Kurumadde, $\mathrm{g} l^{-1}$ & $24.9 \pm 0.50$ & $25.5 \pm 0.37$ & 0.145 \\
\hline Kül, g $l^{-1}$ & $2.2 \pm 0.04$ & $2.1 \pm 0.03$ & 0.082 \\
\hline Bağlı $\mathrm{SO}_{2}, \mathrm{mg} l^{-1}$ & $79.1 \pm 1.58$ & $83.9 \pm 1.36$ & 0.062 \\
\hline Serbest $\mathrm{SO}_{2}, \mathrm{mg} l^{-1}$ & $13.3 \pm 0.27$ & $12.9 \pm 0.19$ & 0.089 \\
\hline Tanen, $\mathrm{g} l^{-1}$ & $3.6 \pm 0.07$ & $4.2 \pm 0.06$ & 0.000 \\
\hline Renk yoğunluğu & $1.2 \pm 0.02$ & $1.3 \pm 0.02$ & 0.064 \\
\hline Renk tonu & $0.6 \pm 0.01$ & $0.5 \pm 0.01$ & 0.062 \\
\hline$\%$ OY420 & $31.3 \pm 0.63$ & $30.3 \pm 0.44$ & 0.075 \\
\hline$\%$ OY520 & $56.7 \pm 1.13$ & $61.9 \pm 0.89$ & 0.004 \\
\hline$\%$ OY620 & $12.1 \pm 0.24$ & $7.7 \pm 0.11$ & 0.000 \\
\hline$\% \mathrm{dA}$ & $61.8 \pm 1.24$ & $69.3 \pm 1.00$ & 0.001 \\
\hline
\end{tabular}

${ }^{\mathrm{a}}$ Asetik asit cinsinden

Çizelge 3-Şarapların antosiyanin bileşimleri

Table 3-Anthocyanin composition of wines

\begin{tabular}{|c|c|c|c|c|}
\hline & & Kontrol & Soğuk mas. & \\
\hline Antosiyaninler & Pikno & $m g l^{-1}$ & $m g l^{-1}$ & $P$ değgerleri \\
\hline Delfinidin-3-glikozit & 1 & $13.67 \pm 0.21$ & $15.03 \pm 0.23$ & 0.002 \\
\hline Siyanidin-3-glikozit & 2 & $2.17 \pm 0.04$ & $2.54 \pm 0.04$ & 0.000 \\
\hline Petunidin-3-glikozit & 3 & $24.92 \pm 0.50$ & $27.12 \pm 0.39$ & 0.004 \\
\hline Peonidin-3-glikozit & 4 & $14.13 \pm 0.28$ & $15.57 \pm 0.22$ & 0.002 \\
\hline Malvidin-3-glikozit & 5 & $145.70 \pm 2.91$ & $174.22 \pm 2.51$ & 0.000 \\
\hline Delfinidin-3-glikozit-asetat & 6 & $1.46 \pm 0.03$ & $1.71 \pm 0.02$ & 0.052 \\
\hline Siyanidin-3-glikozit-asetat & 7 & $0.54 \pm 0.01$ & $0.63 \pm 0.01$ & 0.086 \\
\hline Petunidin-3-glikozit-asetat & 8 & $2.51 \pm 0.05$ & $2.64 \pm 0.04$ & 0.026 \\
\hline Peonidin-3-glikozit-asetat & 9 & $1.95 \pm 0.04$ & $2.09 \pm 0.03$ & 0.092 \\
\hline Malvidin-3-glikozit-asetat & 10 & $17.59 \pm 0.35$ & $20.34 \pm 0.29$ & 0.001 \\
\hline $\begin{array}{l}\text { Delfinidin-3-glikozit- } p \text { - } \\
\text { kumarat }\end{array}$ & 11 & $0.58 \pm 0.01$ & $0.69 \pm 0.01$ & 0.053 \\
\hline $\begin{array}{l}\text { Petunidin-3-glikozit- } p \text { - } \\
\text { kumarat }\end{array}$ & 12 & $1.80 \pm 0.04$ & $2.11 \pm 0.03$ & 0.000 \\
\hline $\begin{array}{l}\text { Peonidin-3-glikozit- } p \text { - } \\
\text { kumarat }\end{array}$ & 13 & $2.19 \pm 0.04$ & $2.57 \pm 0.04$ & 0.029 \\
\hline $\begin{array}{l}\text { Malvidin-3-glikozit- } p \text { - } \\
\text { kumarat }\end{array}$ & 14 & $14.40 \pm 0.29$ & $16.89 \pm 0.24$ & 0.000 \\
\hline Toplam & & $243.62 \pm 4.87$ & $284.15 \pm 4.10$ & \\
\hline
\end{tabular}




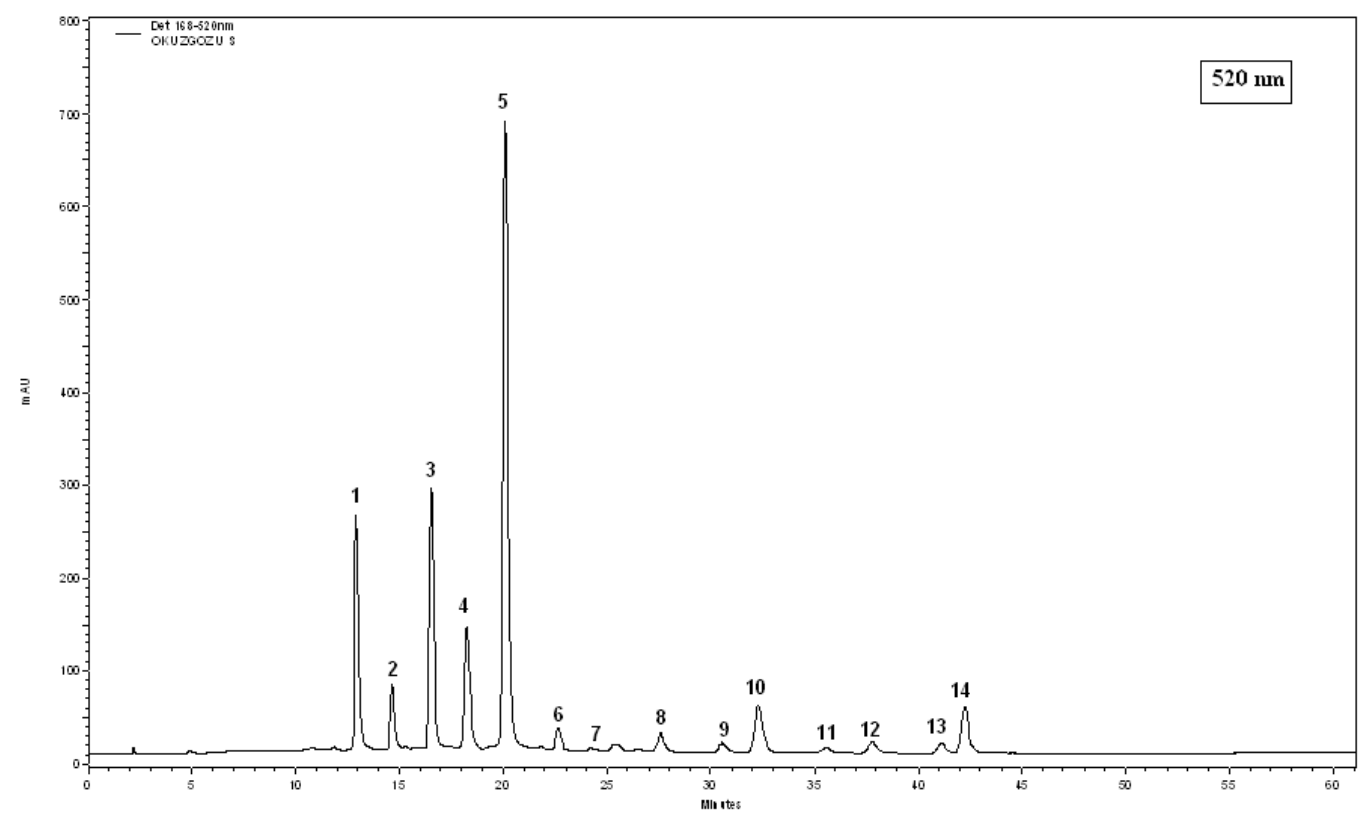

Şekil 1-Şaraplardaki antosiyaninlerin 520 nm'deki HPLC kromatgramı

Figure 1-HPLC chromatogram of anthocyanins in wines at $520 \mathrm{~nm}$

(1: Delfinidin-3-glikozit, 2: Siyanidin-3-glikozit, 3: Petunidin-3-glikozit, 4: Peonidin-3-glikozit, 5: Malvidin-3-glikozit, 6: Delfinidin-3glikozit-asetat, 7: Siyanidin-3-glikozit-asetat, 8: Petunidin-3-glikozit-asetat, 9: Peonidin-3-glikozit-asetat, 10: Malvidin-3-glikozit-asetat, 11: Delfinidin-3-glikozit-p-kumarat, 12: Petunidin-3-glikozit-p-kumarat, 13:Peonidin-3-glikozit-p-kumarat, 14: Malvidin-3-glikozit-p-kumarat)

yükseltmiştir. Benzer bulgular İspanyol Monastrell şarabında da bildirilmiştir (Álvarez et al 2006). Araştırmacılar kontrol şarabında malvidin-3glikozit miktarını $167.42 \mathrm{mg} l^{-1}$ olarak saptarken, soğuk maserasyon uygulamasının bu bileşiğin miktarını $\quad 184.99 \quad \mathrm{mg} \quad l^{-1}$ ye çıkardığını vurgulamışlardır. Her iki şarapta, glikozit formunda malvidin-3-glikozitten sonra miktar olarak en fazla petunidin-3-glikozit bulunmuş ve bunu peonidin-3glikozit izlemiştir. Siyanidin-3-glikozit en düşük konsantrasyonda bulunan glikozit yapida antosiyanin olup, bu bileşiğin miktarı tanıkta 2.17 $\mathrm{mg} l^{-1}$ iken, soğuk maserasyon şarabında $2.54 \mathrm{mg} l^{-1}$ olarak saptanmıştır.

Asetil formunda delfinidin, siyanidin, petunidin, peonidin ve malvidin olmak üzere toplam 5 adet antosiyanin belirlenmiştir Kontrol şarabında asetil formundaki antosiyaninlerin toplam miktarı 24.05 $\mathrm{mg} l^{-1}$ ve soğuk maserasyon uygulamasiyla elde edilen şarapta ise $27.41 \mathrm{mg} l^{-1}$ dir. Soğuk maserasyon uygulaması bu bileşiklerin miktarını \% 12.7 oranında artırmıştır. Malvidin-3-glikozit-asetil, kontrol ve soğuk maserasyon uygulamasiyla elde edilen şaraplarda miktar olarak en fazla bulunan asetil yapılı bileşiktir. Benzer şekilde, GomezMiguez et al (2007) Syrah üzümlerine uygulanan soğuk maserasyon uygulamasının şarapların asetil formundaki antosiyaninlerin toplam miktarını 53.29 $\mathrm{mg} \quad l^{-1}$, den $103.65 \mathrm{mg} \quad l^{1}$,ye yükselttiğini bildirmişlerdir.

Kumaril formunda 4 adet antosiyanin (pik no: 11-14) belirlenmiştir. $\mathrm{Bu}$ bileşikler içerisinde malvinidin-3- $p$-kumaril, glikozit ve asetil formunda olduğu gibi, en baskın bileşiktir. $\mathrm{Bu}$ bileşiğin miktarı kontrol şarapta $14.40 \mathrm{mg} l^{-1}$ iken soğuk maserasyon uygulamasiyla $16.89 \mathrm{mg} l^{-1}$ ye yükselmiştir.

\section{4. Şarapların duyusal özellikleri}

Öküzgözü üzümlerinden elde edilen şarapların duyusal değerlendirilmesinde renk, aroma, dolgunluk, tatlılık, ekşilik, acılık, burukluk, son burukluk ve genel izlenim özellikleri temel alınmıştır. Şekil 2'de görüldüğü gibi, soğuk 


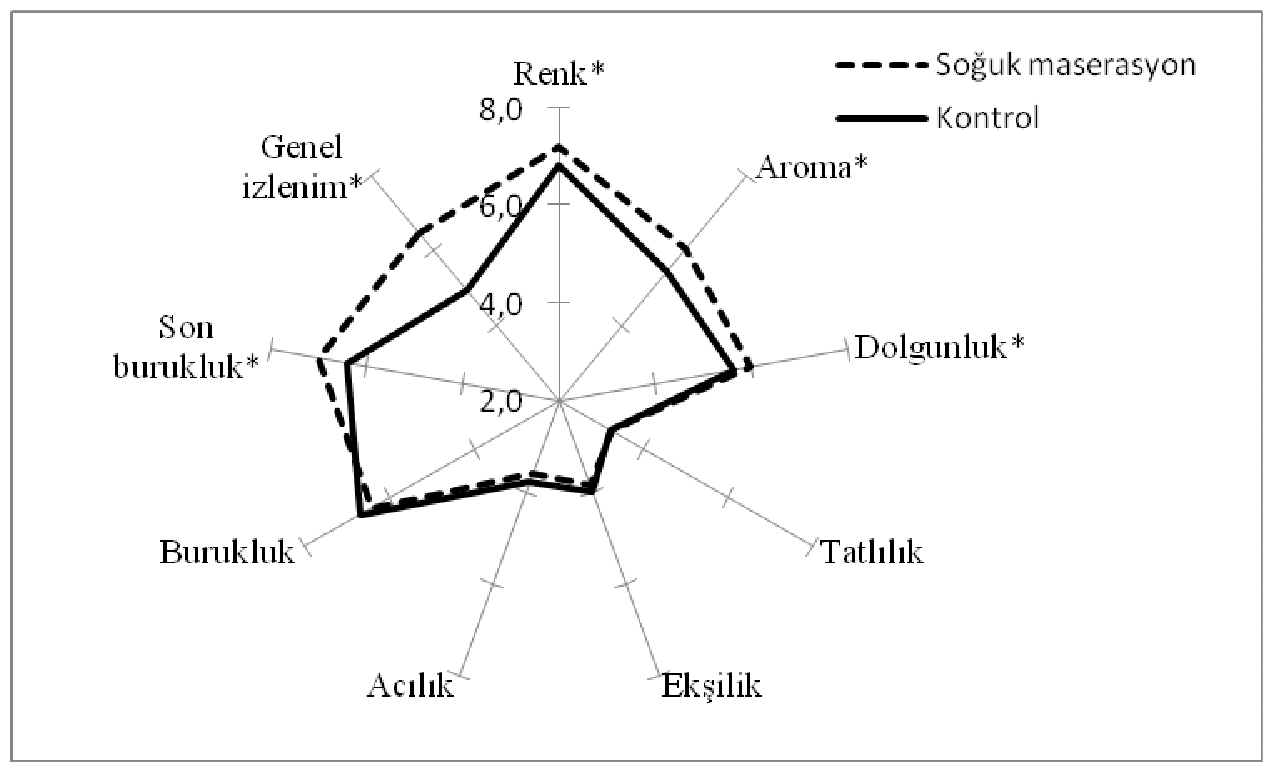

Şekil 2-Şaraplarının lezzet profili analiz sonuçları $(P<0.05)$

Figure 2-Sensory profiles of Öküzgözzü wines

maserasyon yöntemiyle elde edilen şaraplar renk, aroma, genel izlenim ve son burukluk bakımından kontrol şarabına göre daha çok beğenilerek yüksek puanlar almış ve oluşan farklılık istatistiksel $(P<0.05)$ açıdan önemli bulunmuştur. Soğuk maserasyon uygulamasının şarapların fenol bileşikleri üzerindeki etkileri yapılan duyusal analizlerle (renk ve son burukluk) de doğrulanmıştır.

\section{Sonuçlar}

Soğuk maserasyon uygulamasının şarapların antosiyanin, tanen, toplam fenol bileşikleri ve renk bileşimi üzerine önemli etkisinin olduğu saptanmıştır. Soğuk maserasyon uygulamasıyla elde edilen şaraplarda antosiyanin ve tanen miktarları artmıştır. Yapılan duyusal değerlendirmede, soğuk maserasyon yöntemiyle üretilen şaraplar renk, aroma ve genel izlenim bakımından kontrol şarabına göre daha yüksek puanlar almıştır. Bu bulgular göz önünde bulundurularak, ülkemizin önemli siyah şaraplık çeşitlerinden biri olan Öküzgözü üzümleri üzerinde benzer araştırmalar sürdürülmeli ve elde edilen verilerle bu çeşidin karakteristik özelliklerine daha belirgin bir nitelik kazandırılmalıdır. Öte yandan, soğuk maserasyon uygulamalarında farklı sıcaklık ve sürelerin çalışılması bu çeşidin antosiyanin ve fenol profilinin geliştirilmesine katkıda bulunacaktır.

\section{Kaynaklar}

Álvarez I, Aleixandre J L, Garcia M J \& Lizama V (2006). Impact of prefermentative maceration on the phenolic and volatile compounds in Monastrell red wines. Analytica Chimica Acta 563: 109-115

Álvarez I, Aleixandre J L, Garcia M J, Lizama V \& Aleixandre-Tudo J L (2009). Effect of the prefermentative addition of copigments on the polyphenolic composition of Tempranillo wines after malolactic fermantation. European Food Research and Technology 228: 501-510

Amerine M A, Berg H V, Kunkee R E, Ough C S, Singleton V L \& Webb A D (1980). The Technology of Wine Making. The AVI Publishing Company, Inc. Westport, Connecticut, $797 \mathrm{~s}$

OIV (1990). Recueil des Methodes Internationales D'Analyse des Vins et des Mouts, Office International de la Vigne et du Vin, Paris, pp. 368

Anlı E R (2004). Farklı şarap işleme yöntemlerinin kalecik karası şarabının fenol bileşimi ve antioksidan kapasitesi üzerine etkisi. Gıda 29(6): 451-455

Canbaş A (1983). Şaraplarda Fenol Bileşikleri ve Bunların Analiz Yöntemleri. Tekel Enstitüleri, Yayın 
No: Tekel 279 EM/003, İstanbul, (16)s

Çopanoğlu E \& Boyacıŏlu D (2006). Tanımlayıcı analiz ve soslarda uygulanması. Türkiye 9. Gıda Kongresi. 24-26 Mayıs, Bolu, Türkiye

Gil-Munoz R, Moreno-Perez A, Vila-Lopez R, Fernandez-Fernandez J I, Martinez-Cutillas A \& Gomez-Plaza E (2009). Influence of low temperature prefermentative techniques on chromatic and phenolic characteristics of Syrah and Cabernet sauvignon wines. European Food Research and Technology 228: 777-788

Girard B, Yüksel D, Cliff M A, Delaquis P \& Reynolds A G (2000). Vinification effects on the sensory, colour and GC profiles of Pinot noir wines from British Columbia. Food Research International 34: 483-499

Gomez-Miguez M, Gonzalez-Miret M L \& Heredia F J (2007). Evolution of colour and anthocyanin composition of Syrah wines elaborated with prefermentative cold maceration. Journal of Food Engineering 79: 271-278

Gómez-Plaza E， Gil-Munoz R, López-Roca JM, Martinez-Cutillas A \& Fernandez JI (2001). Phenolic compounds and color stability of red wines: Effect of skin maceration time. American Journal of Enology and Viticulture 52(3): 266-270

Hereidia F J, Escudero-Gilete M L, Hernanz D, Gordilo B, Melendez-Martinez A J, Vicario I M \& GonzalezMiret M L (2010). Influence of the refrigeration technique on the colour and phenolic composition of Syrah red wines obtained by pre-fermentative cold maceration. Food Chemistry 118: 377-383

Jackson RS (2002). Wine Tasting: A Professional Handbook. Elsevier Academic Press, London, UK
Kelebek H, Canbas A, Selli S, Saucier C, Jourdes M \& Glories, Y (2006). Influence of different maceration times on the anthocyanin composition of wines made from Vitis vinifera L. cvs. Boğazkere and Öküzgözü. Journal of Food Engineering 77 (4): 1012-1017

Mazza G (1995). Anthocyanin in grape and grape products. CRC Critical Rewievs in Food Science and Nutrition 35(4): 341-371

Ough CS \& Amerine MA (1988). Methods for Analysis of Must and Wines, John Wiley and Sons, New York

Parenti A, Spugnoli P, Calamai L, Ferrari S \& Gori C (2004). Effects of cold maceration on red wine quality from Tuscan Sangiovese grape. European Food Research and Technology 218: 360-366

Ribéreau-Gayon P \& Glories Y (1986). Phenolics in grapes and wine. Proceeding of the Sixth Australian Wine Industry Technical Conference, Terry Lee, Adelaide, South Australia. 14-17 July, pp. 247-256

Ribéreau-Gayon P, Glories Y, Maujean A \& Dubourdieau D (2000). Handbook of Enology, Volume 2: The Chemistry of Wine and Stabilization and Treatments. John Wiley and Sons Ltd., England

Rotter B (2008). Prefermantation cold maceration. www.brsquared.org/wine

Selli S, Cabaroglu T, Canbaş A, Erten H \& Nurgel C (2002). Kalecik karası şırasında serbest ve bağlı aroma maddeleri. Tarim Bilimleri Dergisi 8: 333-337

Sims C A \& Bates R P (1994). Effect of skin fermentation time on the phenols, anthocyanins, ellagic acid sediment, and sensory characteristics of a red Vitis rotundifolia wine. American Journal Enology and Viticulture 45(1): 56-62 